\title{
TWEE VROEE REAKSIES VAN GEREFORMEERDE KANT OP KARL BARTH
}

Prof. dr. B. J. Engelbrecht

In 1919 het die eerste uitgawe van die epogmakende "Römerbrief" van Karl Barth verskyn. Van die tweede druk in 1922 sê hy dat "kein Stein mehr auf dem andern" gelaat is nie. So opspraakwekkend was hierdie boek dat in 1929 die 5de druk van die tweede, radikaal-hersiene uitgawe verskyn het. Intussen het nog ander werke van Barth en selfs oor Barth verskyn. Ons noem o.a. sy Der Christ in der Gesellschaft (1920); Das Wort Gottes und die Theologie (1924); Vom Christlichen Leben (1926); Auferstehung der Toten (2. Aufl. 1927), sy preke saam met Eduard Thurneysen Komm Schöpfer Geist, (Dritt Aufl., 7-9 Tausend(!) 1926). Maar 1927 was veral belangrik vanweë die verskyning van Barth se eerste Dogmatiekboek: "Die Christliche Dogmatik im Entwurf. 1 Die Lehre vom Worte Gottes. Prolegomena zur Christlichen Dogmatik". Voor dié datum het dwarsoor die wêreld, maar ook in Nederland wye reaksie op sy teologie ontstaan. In 1926 skryf Max Strauch sy "Theologie Karl Barth's", terwyl Haitjema in Nederland ook in 1926 sy Barth boek die lig laat sien (Prof. dr. Th. L. Haitjema, Karl Barth, Wageningen 1926.) Ander Nederlanders wat gereageer het, was drr. A. H. de Hartog, V. Hepp, Ph. Kohnstamm en di. D. Tromp en O. Noordmans.

Maar ná die verskyning van sy genoemde "Die Christliche Dogmatik im Entwurf", het die penne eintlik in beweging gekom. Wat ons hier wil behandel, is die twee kleinere werkies uit Gereformeerde kring wat albei in 1929 verskyn het (voordragte in 1928) naamlik Dr. J. Hoek, Karl Barth, Kok, Kampen 1929 én Dr. H. W. van der Vaart Smit, De School van Karl Barth en de Marburgsche Philisophie. N V Ruys, Zeist 1929.

Hierdie twee reaksies uit Gereformeerde kring is veral interessant. Hoewel altwee Gereformeerde predikante was, is hulle aanpak en beoordeling van Barth van wyd uiteenlopende aard. Ons wat as't ware in 'n post-Barthiaanse era lewe en perspektief het op die latere ontwikkeling van Barth en op sy wêfeldwye invloed, sal ongetwyfeld kan oordeel wie van drr. Hoek of Smit in hulle evaluasie en veral in hulle toekomsperspektief op Barth die suiwerste siening van sake gehad het. Maar ons sal ook daaruit baie vir vandag kan leer.

\section{Hoek}

Kom ons kyk eers na dr. Hoek se uiteensetting van Barth (veral na aanleiding sy "Dogmatik im Entwurf"). Hy skryf populêr en wil "ten dienste van de meelevende leden onzer Kerken" noodsaaklike inligting (en seker ook waarskuwende woorde) gec oor "dezen zoo snel vermaarden hoogleeraar." Sommer so met die intrapslag maak dr. Hoek kapsie daarteen dat Barth, anders as by "de andere dog matieken ... die hoogstens na enkele korte vóóropmerkingen: met de eigenlijke dogmatiek begint" — dat Barth so 'n "zeer uitvoerige 
prolegomena" gee; dan sê Hoek: "Wie werkelijk iets te zeggen heeft, gevoelt geen behoefte aan een lang voorbereidend en verklarend woord". Wat Hoek nie besef het nie (en wat hier gestel en later deur Barth oor en oor herhaal is) is dat hierdie "Prolegomena" uiten-uit 'n stuk reformatoriese dogmatiek-self is en nie 'n voorafgaande inleiding om eers daarna "de lezers binnen te voeren in het heiligdom der dogmatiek" nie. Die inhoud van hierdie stuk egte dogmatiek, is die belangrike leerstuk oor God se Woord. Trouens, Barth sê self op die binne-titelblad dat hierdie die "erster Band" is wat handel oor "Die Lehre vom Worte Gottes" en hierdie leer noem hy dan die "Prolegomena zur christlichen Dogmatik." Eintlik moes Hoek dié titel raakgelees het en besef het: Hier het ons 'n egte stuk reformatoriese dogmatiek. Ek sê spesifiek: "reformatories", want indien ons die belydenisse van vó́r die Reformasie nagaan, vind ons weinig oor die Woord van God en oor die Bybel. Maar toe die reformatoriese Kerk eers naas die Rooms-katolieke Kerk te staan gekom het en albei hulle op "die openbaring" beroep het, het die vraag ontstaan: Hoe kan twee Kerke met dieselfde uitgangspunt en gegewens (naamlik die openbaring van God) tot sulke teenstrydige leringe kom dat die één die "anathema" teenoor die ander moet uitspreek en die ander weer van die een se leer moet sê: dit is "vervloekte afgodery" ( $\mathrm{Vr}$ en antw 80, Heid. Kateg.)? Besinning hieroor het begin aantoon dat die Protestante se diepste oortuiging was dat die openbaring van God in die Skrif alleen te vinde is, terwyl die Rooms-Katolieke gesê het: "Die Heilige Skrif alleen bevat nie alles wat God openbaar het nie; daarom is die oorlewering noodsaaklik" (Katolieke Katechismus, Oudtshoorn KP., 1941, bl 5). Teenoor die Scriptura sacra ét traditio ecclesiastica (met al sy komponente van auctoritas Patrum, usus ecclesiae etz, etc.) was die sola Scriptura só fundamenteel vir die Reformasie dat dit allerweë as die formele beginsel (ook: principium cognoscendi) van die Pro testantisme erken word (o.a. Alex Schweizer, Glaubenslehre der EvRef Kirche 1844, I, bl 31). En nou is dit juis oor hierdie allerbelangrikste leerstuk ( $\mathrm{nl}$. die leer oor die Woord van God) wat al die ander leerstukke gaan beinnvloed waaroor Barth in sy Prolegomena handel. Dit is dus geensins die gevolg dat Barth "nie veel te sê het", soos Hoek beweer, en dat hy daarom so 'n lang Prolegomena skryf nie. Soos die duisende bladsye van sy latere Kirchliche Dogmatik getuig het hy oneindig baie te sê gehad.

En tog is Hoek se houding teenoor Barth se "Lehre vom Worte Gottes" teen Hoek se eie agtergrond verstaanbaar. Soos A. J. Bronkhorst in sy "Karl Barth" ('s Gravenhage 1953, bl. 34-36) aantoon het die ortodoksie "tegenover de Bijbel-critiek van de vorige eeuw, een systematische apologie van de Bijbel gesteld, die hem verdedigde van de eerste letter van Genesis tot de laatste punt van Openbaring. Wanneer er maar éen foutje in de geheele Schrift zou voorkomen, dan was deze niet meer het onfeilbare woord van God... en dan viel alles." Terwyl Hoek hom teruggetrek het in die skans van hierdie "Skriftapologie" (Bronkhorst), het Hoek nie ingesien dat die 463 bladsye-lange Prolegomena juis bedoel was om op 
wetenskaplike wyse die reformatoriese sola Scriptura te verdedig teen die "felle aanvallen van de moderne en vrijzinnige theologie van de vorige eeuw."

Kort saamgevat kan ons sê dat Barth dit nie soseer teen die Skrifkritiek se metode gehad het nie, maar teenoor die allerarmocdigste resultate daarvan wat, soos Bronkhorst sê, in ieder geval "niet wezenlijk belangrijk voor het belijden der Kerk en voor cle boodschap Gods" was nie. Barth het die mens vergelyk met iemand in die uiters benarde omstandighede van 'n konsentrasiekamp. Nou kom daar 'n brief met ' $n$ bevrydingsboodskap, of van so 'n gevangene se geliefdes. Dit is miskien vol spelfoute, verkreukeld, geskeur. miskien oorgeskryf deur ' $n$ vriend om dit in te kan smokkel. Maar wie só 'n brief ontvang, rig sy aandag nie op die kreukels, vlekke, skeure, spelfoute ens. nie; nee, dit gaan oor die inhoud van hierdie bevrydingsboodskap, om deur en agter alles die egte en gesaghebbende woord van God te hoor! So 'n brief het net so min as wat die sg. Skrifkritiek basies relevant is, ook geen Skrifapologie nodig nie.

Maar agter Hoek se afwysing van hierdie "Prolegomena" van Barth, sit eintlik nog iets anders. In die Duitse teologie het geslagte teoloë ô die Godsbewussyn van die mens, ò die religieuse ervaring, of die openbaring in die geskiedenis as hulle uitgangspunt geneem, "om dan van daaruit het geheele systeem op te zetten en daaraan alle theologische uitspraken te meten" (Bronkhorst, bl. 32). Per slot van sake het die mens altyd die maat van alle dinge gebly. Teenoor die vrysinnigheid, die Neoprotestantisme waarin Schleiermacher (met sy "Gefühl slechthinniger Abhängigkeit" as wese en grond van egte Christelike godsdiens) 'n wesentlike figuur is, het Barth geprotesteer "en neemt hij zijn uitgangspunt in het Woord Gods"! Uit die felle reaksie van linkse liberale teoloë van destyds, blyk dit hoe raak Barth hier geslaan het - weer eens, ter wille van die reformatoriese beginsel: sola Scriptura!

Nou is dit waar dat Barth dikwels (a) in Kierkegaardiaanse terme (soos God as die "Gans Andere", "die absoluut-kwalitatiewe verskil tussen Skepper en skepsel" en in paradokse) of (b) ook in die filosofiese taal van die Marburgse Kantianisme praat. Maar één ding het, dikwels ondanks hierdie terminologie, altyd vas gestaan en dit is dat dit vir Barth gegaan het om "die Skrif alleen" én om: "aan God alleen die eer". Op bladsy 33 van genoemde boek haal Bronkhorst die vraag van iemand aan Barth aan, naamlik: "Professor gibt es denn keine Glaubensgewissheit?" Barth antwoord: "es gibt keine Glaubensgewissheit, aber Er gibt Glaubensgewissheit." Ons saligheid én die sekerheid oor ons saligheid lê nie by ons, by die mens nie, maar by God alleen! "Der Glaube" sê Barth, "lebt von seinem Gegenstand", dit wil sê leef uit God, uit sý openbaring, uit Jesus Christus. Beide die ortodokse Skrifapologie en vrysinnigheid se Skrifkritiek verarm die Skrif tot "rasionaliteit". Die Skrifwaarheid is vir Barth "relasionaliteit", nie om alles relatief te maak nie, maar om die mens in ' $n$ lewende relasie met die lewende God te stel. Dit is iets wat hy by sy leermeester Wilhelm Hermann geleer het. 
Dr. Hoek gee wel toe dat Barth "een zoo snel vermaarden hoog. leeraar is" en weet van sy wêreldwye invloed (alreeds in 1929) en van die uitvoerige en selfs felle diskussies rondom Barth se teologie. Hierdie dinge alleen moes al 'n vingerwysing vir dr. Hoek gewees het dat hier nie net 'n gepraat aan die gang is nie, maar dat hier 'n worsteling rondom fundamentele vrae, vrae veral in die reformatoriese teologie, plaasvind. Ons het die vrae hierbo as die diskussie rondom die sola Scriptura, die leer oor Gods Woord en teen die modernisme en vrysinnige teologie beskryf. 'n Veel beter weg sou vir dr. Hoek gewees het om self in te spring en om hom nie terug te trek in die ivoor-toring van 'n ortodoksisme wat op al die betrokke vrae en probleme pasklaar antwoorde het nie.

Aan die Universiteit van Pretoria het ek Dogmatiek gestudeer o.a. onder prof. S. P. Engelbrecht, 'n fel anti-Barthiaan. Maar toe ek in 1949 by Barth sy openbare universiteitslesings én veral sy doktoraal-privatissima kon bywoon, het ek tog begin agterkom (nieteenstaande my aanvanklike bedenkinge) dat ons hier 'n teoloog het wat met die inset van al sy gawes en kragte niks anders wil doen as om die Bybels-reformatoriese teologie in die moderne tyd en problematiek suiwer te laat klink nie. In die aanpak van feitlik elke probleem het beide die formele beginsel van die Protestantisme (die sola Scriptura, die feit dat die Skrif die enigste bron en maatstaf vir ons geloof en lewe is) én die materiële beginsel (ook die articulus fundamentalis genoem, naamlik die protes teen alle kreatuur-ver(af)goding, die feit dat die mens se saligheid alleen van God afhanklik is) by Barth ' $n$ beslissende en duidelik waarneembare rol gespeel.

Maar nou moet 'n mens toegee dat dr. Hoek se werkie wel baie verdienste het. Ons het veral beswaar gehad teen sy evaluasie en evaluasiewyse van Barth se teologie; maar in sy weergawe van Barth se gedagtes munt hy uit en in sy doel om iets oor Barth te sê "ten dienste van de meelevende leden onzer Kerken" slaag hy goed. Hoek het byvoorbeeld waardering vir die "hartstochtelijk persoonlijke karakter" van Barth se teologie. "Het gaat by Barth altijd om God en om den mensch, gelijk deze tot God in persoonlijke betrekking staat". Hierdie eksistensiële karakter van Barth se teologie bring mee dat Barth telkens "een appēl op het geweten van zijn hoorders en lezers" doen. "Hij wil dat zij zich rekenschap geven van hun relatie met God." Hiervoor het Hoek baie waardering en 6́k vir die feit dat Barth die prediking ("welke zoo vol nood en belofte zijn") so nou by die teologiese refleksie betrek. "Trouwens heel deze dogmatiek is gebouwd op de kerkelijke prediking. Dat is haar uitgangspunt, haar centrum en doel. Dat maakt (sê Hoek) veel van Barth's werk ook zoo theologisch-praktisch."

Ook Hoek se uiteensetting van Barth se dialektiese metode ("met opzet door hem aangewend"), is saaklik korrek. Daarvan sê hy o.a.: "Het ja moet door het neen medebepaald, toegelicht, verduidelijkt worden en omgekeerd." Oor God, sy openbaring en verhouding tot ons "kan slechts paradoxaal gesproken worden." Maar Hoek vind hierdie dialektiese metode van Barth verwerplik; 'n metode 
wat volgens hom, behalwe dat dit moeilike verstaanbaarheid en misverstand meebring, ook lei tot agnostisisme. Maar ons moet daarop wys dat die mense Calvyn ook dikwels verwyt het deur te sê: "Jy maak misbruik van paradokse" (E. Doumerque, La Piété reformée d'après Calvin", Paris, 1907). So besef Calvyn dat wanneer hy oor die gebruik van die aardse goedere praat (Inst. IlI, 6, 10) hy deur die Bybelse inhoud self gedwing word om paradoksaal te praat en te sê: "Ons mag en moet die aardse goedere en middele gebruik én geniet - anders sou dit ondankbaarheid teenoor God vir sy gawes wees. Máár... (en dit is die paradoks) ... ons moet dit tegelyk verag en waardeloos ag teenoor die eintlike waardevolle, die toekomende heerlikheid hierna." Calvyn het besef dat 'n logies-reglynige denke in die teologie dikwels tot rasionalisme lei wat die veelvuldige waarheid van God in 'n menslike sisteem wil indwing.

Gegewe sy metodiese uitgangspunt en besware teen Barth, vind Hoek dat Barth se getuienis aangaande die Skrif (waaroor ons hierbo iets gesê het), aangaande die mens, God, Christus, die heilsfeite en die geloof, beslis in stryd is met die Gereformeerde leer en belydenis. Sy stellende dele in verband met bogenoemde temas is pragtig. In verband met die Godsleer sê hy byvoorbeeld: "Van Schleiermacher's opvattingen en methode is Barth dan ook hartgrondig afkeerig. Dat is voor hem geen theologie, maar fenomenologie van het religieuse bewustzijn, dus eigenlijk anthropologie... Van een theologie die eigenlijk alleen van den mensch spreekt, over zijn religie, zijn belevingen en ervaringen, moet Barth niets hebben ... Ook als God tot ons spreekt... ontbreekt ons daarvoor het orgaan. Alleen hij, aan wien God zich werkelijk openbaart, verstaat de menschelijkc onmacht... op deze wijze alleen meent Barth in staat te zijn om God God te laten blijven en Hem niet met ons vermetel denken... neer te halen op het horizontale vlak van ons aardsche bestaan."

Eintlik sal dit nie sin hê om Hoek se weergawes (partymaal net effens skeef met die oog op kritiek) van Barth se antropologie, Christologie Skrifbeskouing, religiebeskouing asook Barth se geloofs- en heilsfeite-beskouing hier weer te gee nie. Maar elke keer is die oordeel van Hoek daaroor negatief. Ons tref oor elkeen van genoemde leerstukke uitsprake aan soos: "En daarmede wordt de Gereformeerde belijdenis van de verzoening door Christus' voldoe ning verloochend;" "zijn dialektische methode is verwerpelijk", terwyl hy by Barth geen plek vind vir wedergeboorte en bekering nie - iets wat ook later onjuis geblyk te gewees het.

Basies spruit Hoek se kritiek op Barth myns insiens daaruit voort dat hy vanuit 'n statiese opvatting van "de Gereformeerde bclijdenis en leer" nie insien dat Barth juis in 'n stryd om lewe en dood gewikkel is om juis hierdie Bybels-reformatoriese belydenis te handhaaf teenoor ' $n$ Verdiesseitigung, teenoor ' $n$ verhorisontalisering deur 'n groot deel van die teologie destyds. Om sinvol met sy teenstanders te diskusseer, maak Barth wel gebruik van die terme wat hulle ken, naamlik Kierkegaardiaanse en Marburgse-Kantiaanse terme en metodologie. Wie egter goed lees en Barth werklik in sy "Sitz im Leben" leer verstaan het, sal ongetwyfeld vanuit 'n Bybels 
reformatoriese hoek, Barth se teologie veel, veel positiewer waardeer as dr. Hoek destyds.

\section{Van der Vaart Smit}

Dr. Smit se invalshoek in sy studie oor Barth (en sy skool) is heeltemaal anders as dr. Hoek s'n. Dieselfde geld van sy meer geskoolde teikengehoor ("een Theologische Studiekring"). Hy het sy taak beperk. Hy wil "de philosophische praemissen, die aan het uitgangspunt ten grondslag liggen" noukeurig nagaan. En uit die staanspoor uit lewer dr. Smit bewys dat hy besonder goed op hoogte is met die fynsinnighede van die metodeleer asook met die filosofiese en die teologiese diskussies van sy tyd, die "Sitz im Leben" van die fenomeen Karl Barth veral ná die verskyning van sy "Prolegomena", sy "Christliche Dogmatik im Entwurf." In die destydse stryd tussen die realisme én die Kantiaanse Kritisisme (Neokantianisme) in die filosofie en teologie in Europa, skaar Smit hom eksplisiet aan die kant van die realisme. In Nederland is een van sy medestanders De Hartog. Smit het via Lotz se boek, Mikrokosmos, self deur die Kantiaanse Kritisisme beweeg maar stel dat hy realis gebly het. Barth en sy aanhangers in Nederland, soos Haitjema (een van my eie leermeesters in Dogmatiek) se uitgangspunt is egter Kantiaanse Kritisisme. Van wat daar op die spel is in hierdie stryd, is dat vir o.a. prof. C. G. Wagenaar (en mag ek byvoeg dr. Hoek) "het a-b c van de kritische theologie nog verborgen gebleven", soos Haitjema dit uitdruk. Hulle vat "alle volzinnen uit Barth's Römerbrief (en ook Entwurf - Engelbrecht) van den averechts-verkeerden kant op. naamlik dogmatisch-metafisisch." Die realisme (verteenwoordig deur die ortodokse Protestantse teologie) "bedient zich van Plato's denkwijze en ook die scholastiese, Roomse-Katolieke teologie (wat 'scholastisch Aristoteles' denkwijze gebruikt') gaat steeds van het 'zijn' uit om zoo tot 'bewustzijn' te komen." Barth c.s. gaan van die "bewussyn" uit om só tot die "syn" te kom.

(a) Fakties en prakties word vir Barth die "bewussyn" gewek deur die openbaring. 'n Mens kan nie tot die Syn (= God) kom, sonder dat $\mathrm{Hy}$ Hom deur sy Woord en Gees aan ons openbaar nie.

(b) Kenteoreties volg Barth c.s. egter 'n langer weg: Hulle uitgangspunt "is het feit dat er in de wereld eine christeliche Reden", hoe dan ook en welke dan ook bestaan. Vanuit hierdie "Faktum" (Entwurf, bl. 2), hierdie "Phânomen" bl. 47) wil Barth uitgaan. Maar hoe kom hy nou tot die "syn" ("Syn")? Die probleem is dat die faktum van "die christliche Rede von der christlichen Sache" (Entwurf, bl. 30) "auch die christliche Torheit, die christliche Hochmut, die christliche Irrlehre und vor allem das christliche Geschwätz" bevat, "auch in den bedeutsamsten christlichen Rede" (Entwurf, bl. 19). Daarom moet hierdie "christliche Rede" na haar inhoud getoets word, krities beoordeel (vandaar: Kritisisme) om die "reine Form dieser christlichen Rede" te vind, die suiwere, die egte spreke. "Kritiek" volgens Kant, "beteekent be-oordeling" (Smit, bl. 8). Die maatstawwe van hierdie beoordeling "worden dialectisch gevonden" deur in alle "christliche Rede in der Welt... ihre eigene 
immanente Logik" op te spoor en te sien wat hulle eintlik meinen muss ... wenn sie wirklich sein will, was sie heisst: christliche Rede" (bl. 2). Fynsinnig merk Smit op dat tussen "was sie meinen" én "was sie meinen muss", die prinsipe van die dialektiek lê as die "normen-erkennende principe". Dan word as karaktertrekke van hierdie "reine Form" van die "christliche Rede", die maatstawwe van "Auftragmässigkeit, Verantwortlichkeit en Glaubenswürdigkeit" gevind. In hierdie "suiwer idee van die Christelike spreke", vind ons egter 'n "Hinweiss" wat uitloop op die "Deus dixit", die Woord van God. Miskien is daar nog tussenstappe tussen die aanvanklike "Wortphänomen" en die "Hinweiss" wat in die christelike geloof heenwys na die transcendente, almagtige God wat sy Woord in die wêreld gestuur het, dié Woord wat die "Ursprung" van die "Idee der christlichen Pfredigt" is; hierdie Woord, hierdie "Deus dixit" is die feit dat God Hom openbaar, dat Hy gespreek het en spreek (Smit, bl. 14). Nou wys Smit daarop dat Barth se "krities-dialektiese Kantiaanse dialektiek" voortgaan met "die Kunst des Zuendefragens", die kuns daarvan om end-uit te vra. Die "immanente Logik" van die sinsnede dat "God spreek", het 'n subjek, 'n predikaat en 'n objek. Dus: "Gott allein ist der Offenbarer. Er ist ganz Offenbarung. Er selber ist der Offenbarte". So kom Barth in sy Entwurf tot die behandeling (kortliks) van die Triniteit, die Vleeswording van die Woord, die Twee-natureleer van Christus, die Wonderbare Ge boorte en die Werk van die Heilige Gees. Dit lyk vir Smit asof Barth nou van die formele oorgaan na die inhoudelike van die Dogmatiek. Maar volgens my was hy eintlik nog altyd met die inhoud besig. Hy het 'n egte inhoudsvraag, die leer van die Woord, net op Kantiaanskritisistiese wyse behandel.

Op hierdie punt het Smit vanuit sy "realistiese" standpunt baie kritiek teenoor Barth c.s. se "kritisistiese" behandelingswyse. Hy meen dat Barth êrens 'n sprong moes maak om vanuit die "bewussyn" tot die "Syn", tot die drie-enige God (en die genoemde leerstukke) te kom. Hy stel (bl. 10) "Dialektisch-critisch kan men van het subjectieve (bewustzijn) nooit tot het objectieve (die Syn) komen, indien men niet eerst met het objectieve begonnen is ..." Nou meen ek (met Haitjema) dat Barth se probleemstelling altyd teologies was en nooit filosofies nie. Hy het met die drie-enige God en sy openbaring begin en slegs via die neo-kantiaanse terme en metodiek met die drie-enige God soos Hy Hom in Christus deur sy Woord geopenbaar het, geëindig. Dit is 'n sirkel-redenering wat meermale by Barth voorkom. Nou wat was die voordeel van dié oefening: Smit sien dit op fynsinnige wyse skerp raak as hy sê: "In de wetenschappelijke wereld namelijk is sinds tientallen van jaren het neo-kantianisme de overheerschende cultuurstroming. En de kerk heeft wel enigermate verband met deze cultuurstroming verloren." Die gevolg was dat "de wetenschappelijke wereld slechts... niet-theologische religieuse philosophie, geen werkelijke theolorie kent." Deur Barth c.s. het dit gebeur dat "het openbaringsbegrip plotseling voor de neo-kantiaansche wereld weer "wetenschappelijk" geworden is. De neo-kantiaan hoort weer theologie... De moderne wereld "hoort" 
den theoloog weer...". Die Christelike teologie en prediking het plotseling 'n faktor geword om daarmee "opnieuw rekening te houden. En dit is een geweldige overwinning van de wereld door het geloof"! (bl. 16 en 17).

Die vorm van hierdie teologie van Barth is uit bostaande bekend. Maar wat is die inhoud daarvan? Op bladsy 10 sê Smit alreeds: "Zoo klimt Barth dus critisch-dialektisch van de woord-phaenomena tot de normen en van de normen tot de idee, dat is tot de orthodoxe prediking der orthodoxe kerk, gelijk hij als orthodox en Gereformeerd man die liefheeft" (ons kursivering). Hy sien Barth se werk as 'een 'Ringen' (worsteling) als geloovig Christen met de moderne denkwereld, een 'Ringen' uiterlijk en innerlijk en met aan vaarding van die praemissen dezer denkwereld." Barth se werke laat "het oude geloofsgetuigenis der Christelijke Kerk, de oude Gereformeerde geloofswaarheden in de moderne cultuurwereld doorklinken" (bl. 17). Hy wys op bl. 15 daarop "dat Barth de dogmata welke hij in zijn "Prolegomena" behandelt, op Gereformeerde wijze (in algemene sin) behandelt... welnu, als Barth Gereformeerd wil heten en Calvinist wil zijn, dient hem in dezen zin zeer zeker de eere te gegeven worden, die hij vraagt. Hij is Gereformeerd en Calvinist." Smit het sekere besware teen Barth; hy het selfs prinsipieel metodiese besware (soos aangetoon: rcalis teenoor kritisis). "Maar dat neemt toch niet weg dat wat Barth positief geeft en doet, waardeering, ook geloofswaardeering verdient en de eerenaam "Gereformeerde" en "Calvinist" te zijn, hem toekomt" (bl. 15 en 16). In my studie van Barth en veral in my studietyd onder Barth, het ek tot presies dieselfde konklusie gekom.

Die punte wat ek wil stel, is seker uit bostaande duidelik:

(i) Ons in Suid-Afrika moet oppas dat ons ons in die huidige teologiese diskussie nie terugtrek en met 'n "Skrifapologetiek" (soos vroeër by Hoek genoem) verskans nie. Dit is maklik en seker ook gerusstellend om ou Gereformeerde waarhede vandag te herhaal. Dit is veel moeiliker en dit vra harde werk om hulle weer hoorbaar te maak in die moderne teologiese, filosofiese en tegnokratiese wêreld soos Barth dit in sy tyd vir sy tyd gedoen het. Ons moet oppas dat daar nie van ons gesê kan word nie, soos van drr. Hoek en Wagenaar destyds gesê is, dat vir ons "die a-bc- van die kritiese teologie (vir ons: van die sg. "theologie nouvelle") verborge gebly het." Ons sal die Nuwe Teologie in sy konteks moet lees en verstaan; maar dit vra baie harde studie en werk.

(ii) Dikwels vanweë die gebrek aan egte kennis van Barth se teologie, is hy vanuit Gereformeerde hoek, dikwels met gebruikmaking en herhaling van ' $n$ sekere kwantum bekende terme, baie negatief beoordeel. Ek self is van oordeel dat ons in Barth juis vandag 'n magtige, Gereformeerde, Calvinistiese bondgenoot het, in ons stryd teen (en ongelukkig gebruik ek hier ook 'n paar effens geykte terme)! - in ons stryd teen die moderne, horisontaliserende, antropologiserende teologie. Een van die hoofmomente in Barth se hele teologiese arbeid was juis teen die Schleiermacheriaanse "teologie", wat volgens Barth niks anders as antropologie was nie! 